\title{
Community Asthma Initiative to Improve Health Outcomes and Reduce Disparities Among Children with Asthma
}

\author{
Elizabeth R. Woods, $\mathrm{MD}^{1}$ \\ Urmi Bhaumik, $\mathrm{ScD}^{1,2}$ \\ Susan J. Sommer, MSN ${ }^{1}$ \\ Elaine Chan, $\mathrm{MS}^{1}$ \\ Lindsay Tsopelas ${ }^{1}$ \\ Eric W. Fleegler, MD ${ }^{3}$ \\ Margarita Lorenzi ${ }^{1}$ \\ Elizabeth M. Klements, $\mathrm{MS}^{4}$ \\ Deborah U. Dickerson ${ }^{2}$ \\ Shari Nethersole, MD 2,5 \\ Rick Dulin ${ }^{6}$ \\ ${ }^{1}$ Division of Adolescent/Young Adult Medicine, Boston Children's Hospital, Boston, Massachusetts \\ ${ }^{2}$ Office of Community Health, Boston Children's Hospital, Boston, Massachusetts \\ ${ }^{3}$ Division of Emergency Medicine, Boston Children's Hospital, Boston, Massachusetts \\ ${ }^{4}$ Medicine Patient Services, Boston Children's Hospital, Boston, Massachusetts \\ ${ }^{5}$ General Pediatrics, Boston Children's Hospital, Boston, Massachusetts \\ ${ }^{6}$ Division of Community Health, National Center for Chronic Disease Prevention and Health Promotion, CDC, Atlanta, Georgia
}

Corresponding author: Elizabeth R. Woods, Division of Adolescent/Young Adult Medicine, Boston Children's Hospital. Telephone: 617-355-6495; E-mail: elizabeth.woods@childrens.harvard.edu.

\section{Summary}

Black and Hispanic children are hospitalized with complications of asthma at much higher rates than white children. The Boston Children's Hospital Community Asthma Initiative (CAI) provides asthma case management and home visits for children from low-income neighborhoods in Boston, Massachusetts, to address raciallethnic health disparities in pediatric asthma outcomes. CAI objectives were to evaluate 1) case management data by parent/guardian report for health outcomes and 2) hospital administrative data for comparison between intervention and comparison groups. Data from parent/guardian reports indicate that CAI decreased the number of children with any (one or more) asthma-related hospitalizations (decrease of $79 \%$ at 12 months) and any asthma-related emergency department visits (decrease of 56\% at 12 months) among children served, most of whom were non-Hispanic black or Hispanic. Hospital administrative data also indicate that the number of asthma-related hospitalizations per child significantly decreased among CAI participants compared with a comparison group. The CAI model has been replicated in other cities and states with adaptations to local cultural and systems variations. Health outcome and cost data have been used to contribute to a business case to educate legislators and insurers about outcomes and costs for this enhanced approach to care. Strong partnerships with public health, community, and housing agencies have allowed CAI to leverage its outcomes to expand systemic changes locally and statewide to reduce asthma morbidity.

\section{Introduction}

Asthma, one of the most common chronic illnesses in the United States, has reached historically high national prevalence rates (i.e., $9.5 \%$ for children aged $\leq 18$ years) $(1,2)$. Furthermore, racial/ethnic disparities in asthma prevalence are substantial $(1,2)$. Evidence from national randomized clinical trials (3-6), previous models of culturally sensitive care (6-9), and National Asthma Education and Prevention Program 2007 guidelines $(10)$ indicates that comprehensive community-based approaches are highly effective in reducing environmental allergens, missed school days, and emergency department (ED) visits, as well as increasing symptom-free days. The Guide to
Community Preventive Services also recommends home-based education and interventions to reduce home environmental triggers of asthma, as well as asthma education and social supports to improve outcomes for children with asthma $(11,12)$. Quality improvement evaluation approaches have been developed that can monitor multifactorial interventions to improve outcomes such as ED visits and hospitalizations for asthma (13) that are consistent with the national guidelines (10). All levels of the socioecological model, including interventions involving individual persons, communities, and systems (e.g., health care payment reform to allow for sustainable funding for programs such as CAI), are essential for improving health outcomes $(14,15)$. 
Asthma can be managed effectively when children and families receive asthma education, understand medications, live in healthy housing, and have a system of coordinated care in place $(16,17)$. Multiple social determinants of health contribute to asthma disparities: low household income; environmental inequities (e.g., outdoor air pollution and substandard housing) and living in poor communities $(18,19)$; exposure to pests, mold, air pollution (including secondhand smoke); and high levels of stress due to community violence (20). Major barriers to health care access in poor communities include lack of adequate health insurance coverage, overwhelmed clinics, shortages of culturally and linguistically competent providers, and low health literacy $(21-24)$.

Asthma was the leading cause of hospitalization at Boston Children's Hospital (referred to as Boston Children's) in Boston, Massachusetts (Boston Children's, unpublished data, 2003), which suggested an important area for pediatric care improvement. The substantial prevalence of pediatric asthma in Boston, Massachusetts, also was reflected in a 2003-2004 surveillance study of asthma prevalence in Massachusetts schools (grades kindergarten through 8), which indicated that the overall asthma prevalence in Boston schools was $16 \%$, with five Boston schools reporting rates of $>24 \%$ (25). In 2004, rates of asthma-related hospitalizations among children aged $<5$ years in Boston were almost five times higher for nonHispanic black children (referred to as black in this report) (14.2 per 1,000 population) and Hispanic children (14.1 per $1,000)$ compared with non-Hispanic white children (referred to as white in this report) $(2.9$ per 1,000) $(26)$. Seventy percent of the children hospitalized for asthma at Boston Children's were from five Boston neighborhoods (Boston Children's, unpublished data, 2003) with higher rates of poverty (census block groups with $\geq 20 \%$ of the population living below the federal poverty level) and primarily black and Hispanic populations (census blocks groups in which blacks, Hispanics, or both comprise $\geq 50 \%$ of the population).

The Community Asthma Initiative (CAI), which is based at Boston Children's, is an enhanced model of care in which nurses and community health workers (CHWs) provide communitybased asthma case management and home visits. CAI was developed to decrease asthma morbidity for children aged 2-18 years with poorly controlled asthma. Before the initiation of the CAI program, Boston Children's Office of Community Health had conducted a 2-year community needs assessment using a community participatory approach, which identified asthma as an important area for intervention. CAI initially focused on children living in four ZIP codes of the Roxbury and Jamaica Plain neighborhoods of Boston that had high rates of poverty and asthma and were near Boston Children's and the hospital's community health center (Figure 1) $(27,28)$.
The program was launched in 2005 with philanthropic and community benefits funds. In 2007, CAI received a 5-year grant from CDC's Racial and Ethnic Approaches to Community Health (REACH) program to address asthma health disparities and underlying social determinants of health while continuing to provide comprehensive asthma home visits. This report describes outcomes and evaluations of the CAI program during 2005-2012.

CDC's Office of Minority Health and Health Equity selected the intervention analysis and discussion that follows to provide an example of a program that might be effective in reducing asthma-related disparities in the United States. Criteria for selecting this program are described in the Background and Rationale for this supplement (29).

\section{Methods}

\section{Intervention Methods}

CAI hired bicultural, Spanish-speaking CHWs to provide enhanced asthma care to families through case management and home visiting services. Case management services included working with landlords, property managers, and the public housing authority on housing code violations such as pests and mold; referrals to City of Boston Inspectional Services, legal services, food pantries, and smoking cessation resources; and assessment of eligibility and assistance obtaining benefits and services, such as food stamps, Medicaid, shelter or day care placement, and tutoring. Home visits involved 1) individualized asthma education, care coordination, and connection to primary care, asthma specialists, and community resources; 2) home environmental assessment and remediation with provision of allergen-proof bedding encasements and high-efficiency particulate air (HEPA) filter vacuum cleaners; 3) education regarding use of green cleaning methods, such as use of low volatile organic compound (VOC) products; 4) integrated pest management (IPM) materials and instruction and referrals to Boston Inspectional Services Department as needed to address state sanitary code violations (30); 5) visits by a private IPM company when necessary; and 6) encouragement of smoking cessation among parents and guardians and of smoke-free homes.

The program partnered with local organizations providing care for children, including state and city public health agencies, community health centers, Boston Public Schools, Head Start, after-school programs, the Boys \& Girls Clubs of America, and the Greater Boston Young Men's Christian Association (YMCA) to address social determinants of health that affect asthma and to promote system change beyond what can be performed in the individual home. This included 
FIGURE 1. Boston, Massachusetts, neighborhoods in the Boston Children's Hospital Community Asthma Initiative, including the pilot intervention communities (Roxbury and Jamaica Plain) and comparison communities (North Dorchester and South Dorchester)

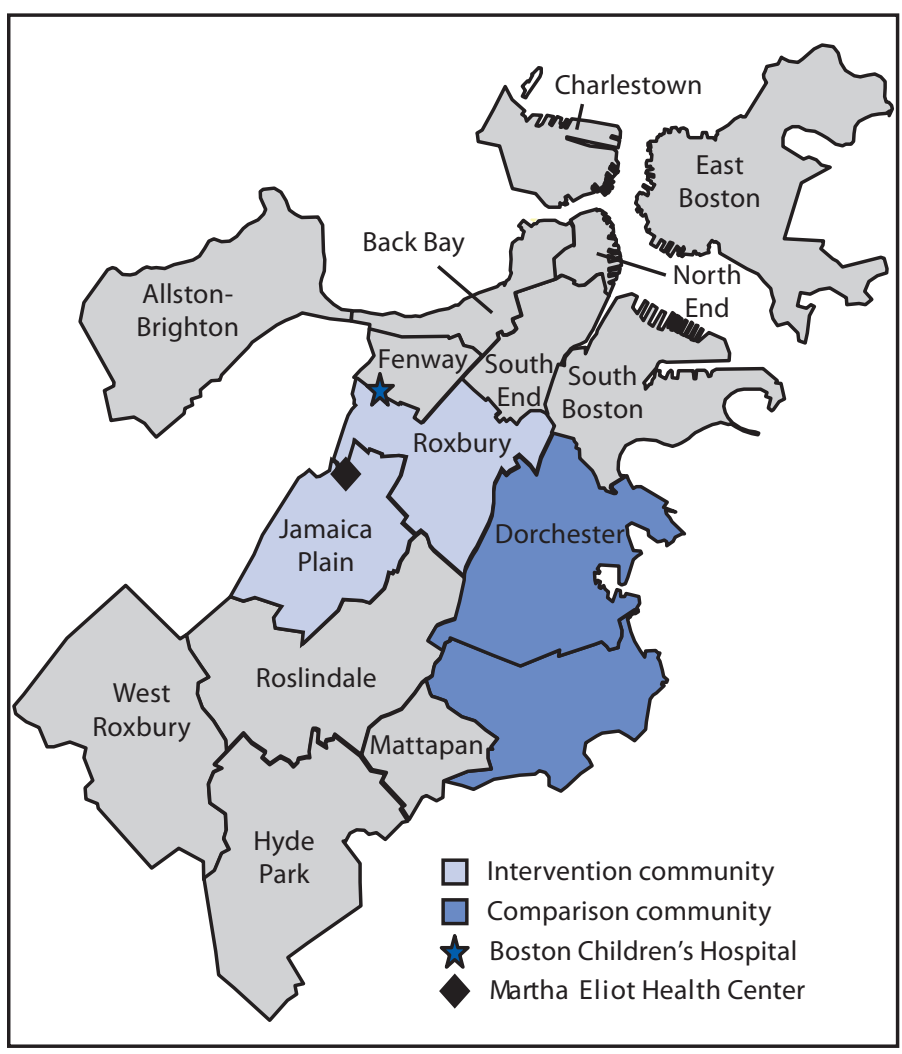

collaboration among local and regional asthma healthy housing and healthy schools coalitions to address indoor air quality in schools and homes (31) and among regional and national agencies to develop a business case and educate legislators and insurers about outcomes and costs for this enhanced approach to care. CAI has active community and family advisory boards, which contributed recommendations that have been incorporated into the program.

\section{Data Collection and Analysis}

\section{Longitudinal Evaluation of CAI Participants}

Nurses reviewed administrative logs of ED visits and hospitalizations and identified children with asthma-related diagnoses. The enrollment event was defined as an ED visit or hospitalization for an asthma exacerbation as reflected in the primary or secondary diagnosis. Enrollment criteria included the following:

1. Aged 2-18 years

2. From Roxbury or Jamaica Plain during the initial pilot and subsequently Dorchester and then other Boston ZIP codes with high levels of poverty (i.e., $\geq 20 \%$ of the population below the federal poverty level) $(32,33)$ and high annual rates of asthma hospitalizations during 1999-2003 for children aged $<5$ years ( 14.8 per 1,000 population in Roxbury, 9.7 per 1,000 population in Jamaica Plain, 11.4 per 1,000 population in South Dorchester, and 13.7 per 1,000 population in North Dorchester) (26)

3. One or more hospitalizations, ED visits, or courses of oral corticosteroids (referred to as high-risk asthma in this report) in the past 12 months

4. Referral because of poorly controlled asthma as defined by the National Asthma Education and Prevention Program 2007 guidelines (10), which take into account frequency of day and nighttime coughing, wheezing, and shortness of breath and interference with normal activities such as exercise, frequency of use of short-acting bronchodilators, and number of exacerbations requiring oral systemic corticosteroids

Eligible participants were seen face-to-face during hospitalizations or contacted by telephone, and all were offered the full range of CAI services. Intervention participants were enrolled in the program during October 1, 2005-March 31, 2012, which includes the initial pilot in Roxbury and Jamaica Plain and subsequent expansion of the program to other Boston ZIP codes. This is a larger case management sample than analyzed previously $(27,28)$. Nurses, CHWs, or both documented participant adherence to medication and treatment plans, as well as home environmental findings, using an assessment tool adapted from the National Center for Healthy Housing Pediatric Environmental Home Assessment form (34).

Data were collected by parent/guardian report via faceto-face interviews in the hospital or by telephone as part of clinical care (reflecting back 6 months) at three time points: enrollment (i.e., enrollment date, which is referred to as baseline for the case management data in this report), 6 months after enrollment, and 12 months after enrollment. These data included daytime and nighttime asthma symptoms (defined as coughing, wheezing, or shortness of breath in the past 2 weeks), missed school days (defined as school absences due to asthma in the past 6 months), missed parent/guardian workdays (defined as work absences due to the child's asthma in the past 6 months), days of limitation of physical activity (defined as the need to slow down or stop playing due to asthma in the past 2 weeks), and number of ED visits and hospitalizations (defined as those with asthma exacerbation with or without status asthmaticus as the primary or secondary diagnosis). An attrition analysis was performed comparing initial demographic variables at baseline, 6 months, and 12 months. 
Number of events (ED visits or hospitalizations) or days (of missed school, of missed parent/guardian workdays, or limitation of physical activity) were treated as dichotomous (zero versus one or more) or continuous variables. The percent decrease was calculated as the baseline value (number of events or days) minus the follow-up value divided by the baseline value. McNemar's test was used for dichotomous variables, and paired t-tests and general linear model repeated measures analysis were used for continuous variables. Results were considered significant at $\mathrm{p}<0.05$. A geographic information system (GIS) analysis of census block distribution of intervention participants examined the relationship between asthma and neighborhood demographics, including federally defined poverty areas, in which $\geq 20 \%$ of the population lives below the federal poverty level $(32,33)$, and neighborhoods that are predominantly black, Hispanic, or both. Boston Children's Institutional Review Board approved the evaluation and access to case management data and hospital administrative databases with a waiver of consent for the enhanced clinical care program.

\section{Comparison of CAI Children with Those in Similar Neighborhoods}

The first 33 months of CAI (October 1, 2005-June 30, 2008) were a pilot period, with services limited to four ZIP codes representing Jamaica Plain and Roxbury (after which point enrollment was extended to other ZIP codes in Boston). This initial pilot design allowed early CAI intervention participants to be compared with children in four other ZIP codes in the demographically similar Boston neighborhoods of North Dorchester and South Dorchester, where the intervention was not yet taking place $(27,28)$. Both the intervention group and the comparison group included patients at Boston Children's who had previous asthma-related ED visits or hospitalizations, and the hospital administrative database was used to collect information on ED visits and hospitalizations for both these groups based on the enrollment date for CAI participants and an index date within a similar date range for the comparison group. A correlation analysis was performed to compare parent/guardian reports with hospital administrative data in the intervention group.

Paired t-tests were used to compare total asthma encounters 1 year before and 1 year after the enrollment date within the CAI group, and 1 year before and 1 year after an index date within the comparison group (within-group comparisons) to assess changes in ED visits and hospitalization encounters. Because the comparison group did not have an enrollment date, an index date was chosen for them as the first time the child had an ED visit or hospitalization for asthma during October 1, 2005-September 30, 2006 or October 1, 2007-June 30, 2008. The 1-year gap between these periods was chosen so that there would be no overlap between 1-year back analyses and new participant selection. Unpaired t-tests were used to compare the decrease in $\mathrm{ED}$ visits or hospitalizations from 1 year before to 1 year after the enrollment/index visit date between the CAI participants and the comparison group. To address concerns about normality of the data, nonparametric counterpart tests also were performed as appropriate. In addition, to examine the regression to the mean effect, an analysis of covariance (ANCOVA) analysis was performed to control for this effect.

\section{Results \\ Longitudinal Evaluation of CAI Participants}

During October 1, 2005-March 31, 2012, a total of 908 children were enrolled in the CAI program, which is a larger sample than the sample included in previous publications $(27,28)$ (Table 1). Of these, $56 \%$ were male, $45 \%$ were black, $47 \%$ were Hispanic, and $25 \%$ spoke only Spanish. The average age was 7.3 years (standard deviation [SD]: 4.4; range: 1-21 years); $72 \%$ were Medicaid recipients, and $65 \%$ had a household income of $<\$ 25,000$ (as reported by the parent/ guardian). At enrollment, $56 \%$ of participants were seen face-to-face during their hospitalization. For the 2005-2012 longitudinal evaluation, the attrition analysis showed no differences in demographic variables for the baseline, 6-month, and 12-month follow-up groups (Table 2).

After enrollment, $76 \%$ of participants had at least one home visit, including 689 nurse visits, $305 \mathrm{CHW}$ visits, and 190 combined nurse and CHW visits (Table 3). Home environmental assessments revealed the following risk factors in households on the first visit: $51 \%$ had clutter and dust; $41 \%$, volatile organic compounds; 38\%, carpeting; 36\%, rodents; $26 \%$, pets; $19 \%$, environmental tobacco smoke; $17 \%$, mold; and $12 \%$, cockroaches. IPM services were required for $5 \%$ of families because they had extensive infestations.

At 12 months, significant decreases were found in the dichotomous outcomes of participants with any (one or more) asthma-related hospitalizations (79\% decrease), ED visits (56\% decrease), missed school days ( $42 \%$ decrease), missed parent/guardian workdays (46\% decrease), and days of limited physical activity (29\% decrease) (Table 4$)$. The continuous variables for the decrease in number of asthma-related events or days for these same health outcomes demonstrate significant improvement at follow-up (Table 5). GIS mapping showed that $66 \%$ of families enrolled in CAI lived in a poverty area, and $74 \%$ of families lived in areas that were primarily black, Hispanic, or both (Figure 2). 
TABLE 1. Number and percentage* of children enrolled in the Boston Children's Community Asthma Initiative, by selected demographic characteristics, asthma severity, and type of enrollment - Boston, Massachusetts, 2005-2012

\begin{tabular}{|c|c|}
\hline Characteristic & Baseline $(\mathrm{N}=908)$ \\
\hline Mean age, yrs & 7.3 (SD: 4.4, range: $1-21$ ) \\
\hline $\begin{array}{l}\text { Sex }(\mathrm{N}=908), \text { no. }(\%) \\
\text { Male } \\
\text { Female }\end{array}$ & $\begin{array}{l}507(56) \\
401(44)\end{array}$ \\
\hline $\begin{array}{l}\text { Insurance }(\mathrm{N}=908) \text {, no. }(\%) \\
\text { Medicaid/MassHealth } \\
\text { Private } \\
\text { Other }\end{array}$ & $\begin{array}{r}654(72) \\
233(26) \\
21(2)\end{array}$ \\
\hline $\begin{array}{l}\text { Household income }(\mathrm{N}=840), \text { no. } \\
<\$ 25,000 \\
\$ 25,000-\$ 50,000 \\
>\$ 50,000\end{array}$ & $\begin{array}{l}544(65) \\
196(23) \\
100(12)\end{array}$ \\
\hline $\begin{array}{l}\text { Race/Ethnicity ( } \mathrm{N}=907) \text {, no. (\%) } \\
\text { Hispanic } \\
\text { Black, non-Hispanic } \\
\text { Other }\end{array}$ & $\begin{array}{r}430(47) \\
412(45) \\
65(7)\end{array}$ \\
\hline $\begin{array}{l}\text { Language }(\mathrm{N}=885), \text { no. }(\%) \\
\text { English (monolingual or bilingual) } \\
\text { Spanish (monolingual) } \\
\text { Other }\end{array}$ & $\begin{array}{r}641(72) \\
224(25) \\
20(2)\end{array}$ \\
\hline $\begin{array}{l}\text { Asthma severity category }{ }^{\dagger}(\mathbf{N}=871 \\
\text { Intermittent } \\
\text { Mild persistent } \\
\text { Moderate persistent } \\
\text { Severe persistent }\end{array}$ & $\begin{array}{r}99(11) \\
390(45) \\
308(35) \\
74(8)\end{array}$ \\
\hline $\begin{array}{l}\text { Enrollment }(\mathrm{N}=906), \text { no. }(\%) \\
\text { Face-to-face during hospitalization } \\
\text { By telephone }\end{array}$ & $\begin{array}{l}512(56) \\
394(44)\end{array}$ \\
\hline
\end{tabular}

Abbreviation: $\mathrm{SD}=$ standard deviation.

* Percentages do not include missing data and might not add to $100 \%$ because of rounding.

${ }^{\dagger}$ As defined in the National Heart, Lung, and Blood Institute asthma treatment guidelines (Source: National Heart, Lung, and Blood Institute, National Asthma Education and Prevention Program. Expert Panel Report 3: Guidelines for the diagnosis and management of asthma. Bethesda, MD: National Institutes of Health, National Heart, Lung, and Blood Institute; 2007. http://www.nhlbi.nih. gov/health-pro/guidelines/current/asthma-guidelines).

\section{Comparison of CAI Children with Those in Similar Neighborhoods}

No significant differences between the intervention and the comparison groups were found in demographic variables (Table 6). In the comparison of CAI intervention participants enrolled during the pilot period with children from similar neighborhoods, the mean number of patient hospitalizations for asthma among CAI participants $(\mathrm{N}=268)$ during the pilot period demonstrated a greater decrease between 1 year before and 1 year after the enrollment date compared with the children in the comparison group $(\mathrm{N}=818)$ (Figure 3). The decrease in mean number of asthma-related hospitalizations per child among CAI participants between 1 year before the intervention and 1 year after the intervention was 0.32 hospitalizations per child $(\mathrm{p}<0.001)$, and the decrease in the mean number of hospitalizations for asthma per child in the comparison group was $0.16(\mathrm{p}<0.001)$. A significantly greater decrease occurred in mean number of hospitalizations per child for the intervention group compared with the comparison group from 1 year before to 1 year of follow-up (difference $=0.16$ hospitalizations per child, $\mathrm{p}<0.001$ ).

In contrast, the decrease in mean number of asthma-related ED visits per child among CAI participants ( 0.45 fewer ED visits per child, $\mathrm{p}<0.001)$ was similar to the decrease in the comparison group ( 0.49 fewer ED visits per child, $\mathrm{p}<0.001$ ), with no significant difference in decrease in ED visits between the two groups (difference $=0.04 \mathrm{ED}$ visits per child, $\mathrm{p}=0.49$ ) (Figure 3). For the intervention group, the correlation was high between parent/guardian reports in the case management data and Boston Children's administrative data for hospitalizations $(\mathrm{r}=0.90)$ and $\mathrm{ED}$ visits $(\mathrm{r}=0.85)$.

\section{Community Partnerships}

Boston Children's has worked with the Asthma Regional Council of New England, which is a program of Health Resources in Action that receives funding from the U.S. Department of Health and Human Services and the U.S. Environmental Protection Agency (EPA), and faculty from the University of Massachusetts Lowell to develop a business model for home visit programs for patients with high-risk asthma. The 2010 version includes CAI outcomes and cost analyses (35). In addition, CAI is a member of the Boston Asthma Home Visit Collaborative, convened by the Boston Public Health Commission, which receives funding from EPA and others to share best practices among public health, hospital, health center, payer, and community-based organizations of a nursesupervised CHW model of home visits using a standardized, evidence-based protocol. CAI provided outcome and cost data to the Boston Children's Office of Government Relations and community partners to educate decision-makers and make a case for the potential benefits of a bundled payment pilot project for patients with high-risk asthma within the Massachusetts Medicaid program $(31,36)$. Boston Children's was recently designated as one of three sites in Massachusetts approved to participate in this pilot; implementation will begin pending an agreement with The Commonwealth of Massachusetts Executive Office of Health and Human Services.

\section{Limitations}

The findings in this report are subject to at least three limitations. First, this evaluation was not a randomized controlled trial, and the contributions of individual components of the program to outcomes were not evaluated. 
TABLE 2. Attrition analysis for children enrolled in the Boston Children's Hospital Community Asthma Initiative at baseline and at 6 and 12 months, by selected demographic and insurance characteristics* — Boston, Massachusetts, 2005-2012

\begin{tabular}{|c|c|c|c|c|}
\hline Characteristic & $\begin{array}{c}\text { Baseline } \\
\left(\mathrm{N}=908^{\dagger}\right)\end{array}$ & $\begin{array}{l}6 \text { months } \\
\left(\mathrm{N}=466^{+}\right)\end{array}$ & $\begin{array}{l}12 \text { months } \\
\left(\mathrm{N}=405^{+}\right)\end{array}$ & $p$ value \\
\hline Mean age, yrs & 7.3 (SD: 4.4, range: $1-21$ ) & 7.5 (SD: 4.3, range: 1-21) & 7.5 (SD: 4.3, range: $1-21$ ) & $0.54^{\S}$ \\
\hline $\begin{array}{l}\text { Sex, no. (\%) } \\
\text { Male } \\
\text { Female }\end{array}$ & $\begin{array}{l}507(56) \\
401(44)\end{array}$ & $\begin{array}{l}271(58) \\
195(42)\end{array}$ & $\begin{array}{l}231(57) \\
174(43)\end{array}$ & 0.819 \\
\hline $\begin{array}{l}\text { Insurance, no. (\%) } \\
\text { Medicaid/MassHealth } \\
\text { Private }\end{array}$ & $\begin{array}{l}654(72) \\
233(26)\end{array}$ & $\begin{array}{l}349(76) \\
112(24)\end{array}$ & $\begin{array}{r}308(77) \\
92(23)\end{array}$ & $0.45^{\natural}$ \\
\hline $\begin{array}{l}\text { Race/Ethnicity, no. (\%) } \\
\text { Hispanic } \\
\text { Black, non-Hispanic } \\
\text { Other }\end{array}$ & $\begin{array}{r}430(47) \\
412(45) \\
65(7)\end{array}$ & $\begin{array}{r}229(49) \\
206(44) \\
31(7)\end{array}$ & $\begin{array}{r}205(51) \\
174(43) \\
26(6)\end{array}$ & 0.79 ฯ \\
\hline
\end{tabular}

Abbreviation: $\mathrm{SD}=$ standard deviation.

* Using data collected from parent/guardian.

† Percentages do not include missing data and might not add to $100 \%$ because of rounding.

Based on analysis of variance model.

" Based on chi-square test.

TABLE 3. Services received by children enrolled in the Boston Children's Hospital Community Asthma Initiative - Boston, Massachusetts, 2005-2012

\begin{tabular}{lc}
\hline Services received & No. \\
\hline Total children who received at least one home visit & 692 of $\mathbf{9 0 8}(\mathbf{7 6 \% )}$ \\
Total home visits & $\mathbf{1 , 1 8 4}$ \\
Nurse & 689 \\
CHW & 305 \\
Combined nurse and CHW & 190 \\
IPM extermination visits & $61^{\dagger}$ \\
Children whose households received IPM & 43 of $908(5 \%)$ \\
extermination services & \\
\hline
\end{tabular}

Abbreviations: $\mathrm{CHW}=$ community health worker; IPM $=$ integrated pest management.

* Percentages do not include missing data.

${ }^{\dagger}$ Families might have received more than one extermination visit.

However, national evidence indicates that a comprehensive approach is most effective to address asthma triggers and medication adherence (3-9). Second, 35\% of respondents were lost to follow-up by parent report, and potential biases might have been introduced. However, hospital administrative data were used to provide follow-up and outcome information for all participants, as long as they returned to Boston Children's for subsequent visits. Finally, data obtained from parent/ guardian report might be affected by recall and social response biases. Although hospital administrative data provide accurate information about hospitalizations and ED visits at one institution, these data do not include information on patients who go elsewhere for emergency care. Data collected through parent/guardian reports and from the hospital administrative data were similar in terms of hospitalization and ED visits, indicating that most subsequent events are captured by the hospital administrative data. Access to insurance data will be helpful for evaluating health outcomes and costs due to care among various institutions, as well as all levels of care including primary care visits and pharmacy use.

\section{Discussion}

The CAI model includes home visits with tailored asthma education, case management, and home environment assessments with remediation by nurses, CHWs, or both. Bicultural and Spanish-speaking staff members provided linguistically and culturally sensitive care. The nurses and CHWs worked closely with families of children with asthma to increase follow-up with primary care and specialty providers, obtain and understand an up-to-date asthma action plan, and increase use of urgent care facilities earlier in the course of an asthma exacerbation, rather than waiting to have an even more serious exacerbation treated at an ED. For the majority of families, home environmental remediation was a needed service; parts of Boston have older housing and poor conditions, with substantial mouse and cockroach infestations and mold. HEPA filter vacuum cleaners and bedding encasements were provided to all families due to the high levels of inhalant indoor allergens, combined with the strong prevalence of allergies among enrolled children. IPM supplies and interventions were provided as needed.

The CAI model includes all components of the chronic care model, including addressing patient safety, cultural competency, care coordination, community policies, and case management, for improving the care of patients and families living with a chronic illness $(37,38)$. GIS mapping demonstrated that most families lived in Boston census blocks with high poverty levels and in census blocks with populations that were $\geq 50 \%$ black, Hispanic, or both. 
TABLE 4. Number and percentage of children with selected asthma-related health outcomes* among those enrolled in the Boston Children's Hospital Community Asthma Initiative at baseline, 6 months, and 12 months and percent decreases from baseline to 12 months - Boston, Massachusetts, 2005-2012

\begin{tabular}{|c|c|c|c|c|}
\hline Outcome $^{\dagger}$ & $\begin{array}{c}\text { Baseline } \\
\% \text { (No.) }\end{array}$ & $\begin{array}{l}6 \text { mos }^{\natural} \\
\% \text { (No.) }\end{array}$ & $\begin{array}{c}12 \operatorname{mos}^{* *} \\
\% \text { (No.) }\end{array}$ & $\begin{array}{c}\text { Decrease at } 12 \text { mos } \\
\text { from baseline } \\
\%^{+\dagger}(95 \% \mathrm{Cl})\end{array}$ \\
\hline Any hospital admissions & 60 (241 of 404$)$ & 15 (62 of 404) & $12(41$ of 333$)$ & $79(73-86)$ \\
\hline Any emergency department visits & 53 (213 of 402) & 26 (103 of 402) & 23 (78 of 333) & $56(46-65)$ \\
\hline Any missed school days & 93 (311 of 335) & 55 (185 of 335$)$ & $54(154$ of 286$)$ & $42(36-48)$ \\
\hline Any missed workdays (parent/guardian) & $82(176$ of 216$)$ & 55 (119 of 216$)$ & 44 (76 of 174$)$ & $46(37-56)$ \\
\hline Any days of limitation in physical activity & 55 (223 of 403$)$ & 35 (141 of 403$)$ & 39 (131 of 334$)$ & $29(16-42)$ \\
\hline
\end{tabular}

Abbreviation: $\mathrm{Cl}=$ confidence interval.

* Data were collected by parent/guardian report via face-to-face interviews in the hospital or by telephone as part of clinical care (reflecting back 6 months) at three time points: enrollment (i.e., enrollment date, which is referred to as baseline in this report), 6 months after enrollment, and 12 months after enrollment.

${ }^{\dagger}$ Number of emergency department visits and hospitalizations: those with asthma exacerbation with or without status asthmaticus as the primary or secondary diagnosis; missed school days: school absences due to asthma in the past 6 months; missed parent/guardian workdays: work absences due to the child's asthma in the past 6 months; days of limitation of physical activity: the need to slow down or stop playing due to asthma in the past 2 weeks.

$\S \mathrm{N}=908$.

" $\mathrm{N}=404$.

** $\mathrm{N}=333$.

${ }^{+\dagger}$ The percent decrease is the baseline percent minus the follow-up percent divided by the baseline percent. All decreases are significant ( $p<0.001$ ); $p$ values are based on the Wilcoxon test.

TABLE 5. Mean differences in number of asthma-related health outcomes for children enrolled in the Boston Children's Hospital Community Asthma Initiative at 6 months and 12 months compared with baseline - Boston, Massachusetts, 2005-2012

\begin{tabular}{lrcc}
\hline Outcome* $^{*}$ & $\begin{array}{c}\text { Follow-up } \\
\text { month }^{\dagger}\end{array}$ & $\begin{array}{c}\text { Mean difference } \\
(95 \% \mathrm{Cl})\end{array}$ & $\begin{array}{c}\text { Standard } \\
\text { deviation }\end{array}$ \\
\hline Hospital admissions & $6 \mathrm{mos}$ & $0.51(0.44-0.58)$ & 0.73 \\
& $12 \mathrm{mos}$ & $0.51(0.44-0.58)$ & 0.74 \\
Emergency department & $6 \mathrm{mos}$ & $0.48(0.36-0.60)$ & 1.25 \\
visits & $12 \mathrm{mos}$ & $0.55(0.41-0.69)$ & 1.37 \\
Missed school days & $6 \mathrm{mos}$ & $2.59(1.89-3.29)$ & 7.47 \\
& $12 \mathrm{mos}$ & $2.90(2.16-3.64)$ & 7.21 \\
Missed workdays & $6 \mathrm{mos}$ & $1.36(0.98-1.74)$ & 4.10 \\
(parent/guardian) & $12 \mathrm{mos}$ & $1.25(0.80-1.70)$ & 4.42 \\
Days of limited & $6 \mathrm{mos}$ & $2.28(1.73-2.83)$ & 5.91 \\
physical activity & $12 \mathrm{mos}$ & $1.80(1.19-2.41)$ & 5.97 \\
\hline
\end{tabular}

Abbreviation: $\mathrm{Cl}=$ confidence interval.

* Number of emergency department visits and hospitalizations: those with asthma exacerbation with or without status asthmaticus as the primary or secondary diagnosis; missed school days: school absences due to asthma in the past 6 months; missed parent/guardian workdays: work absences due to the child's asthma in the past 6 months; days of limitation of physical activity: the need to slow down or stop playing due to asthma in the past 2 weeks.

$+\mathrm{N}=908$ at baseline, $\mathrm{n}=404$ at 6 months, and $\mathrm{n}=333$ at 12 months.

$\S$ Number of emergency department visits, hospital admissions, missed school days, parent missed workdays, days of limited physical activity at 6 and 12 months subtracted from the value for baseline ( 6 months before enrollment) divided by the baseline. All differences are significant $(p<0.001) ; p$ values are based on t-tests.

Some changes over time might be a result of regression to the mean; for example, an initial event such as a hospital admission might be an outlier, and the participant might never be admitted again. However, the ANCOVA model with a comparison population accounts for baseline differences (39) as well as community effects due to changes in primary care and community education. CAI intervention participants show a significantly higher decrease in hospitalizations than the comparison group, which accounts for most of the cost savings (because the majority of cost and cost savings are a result of hospitalizations). The children in the intervention group had more hospitalizations than those in the comparison group in the year before their enrollment/index visit (Figure 3). Therefore, the number of ED visits might have been more difficult to influence in the intervention group because children with past hospitalizations might have been those with the most severe asthma symptoms. Accessing insurance claims data is the next step toward expanding the analyses in this report to include a full cost analysis by accounting for all potential events and costs, including costs at other facilities and pharmacies.

Because of the demonstrated success of the pilot program, CAI expanded on July 1, 2008, to serve the comparison ZIP codes and other low-income neighborhoods in Boston. CAI was one of multiple sites for the New England Asthma Regional Council's Centers for Medicare and Medicaid Services Innovation grant to assess the cost effectiveness of CHW home visits with nurse supervision. A major goal of this grant was to work with payers to develop a sustainable funding model, allowing for ongoing services at current sites as well as the potential expansion of services to more patients regionally. In addition, CAI partnered with the American Academy of Pediatrics to replicate CAI in Birmingham, Alabama, and to develop a replication manual (40). UMass Memorial Medical Center in Worcester, Massachusetts, has replicated the program as well.

\section{Conclusion}

CAI has significantly reduced asthma morbidity among black and Hispanic children in Boston. Data from parent/guardian 
FIGURE 2. Distribution of families served by the Boston Children's Hospital Community Asthma Initiative - Boston, Massachusetts, October 1 , 2005-March 30, 2012*

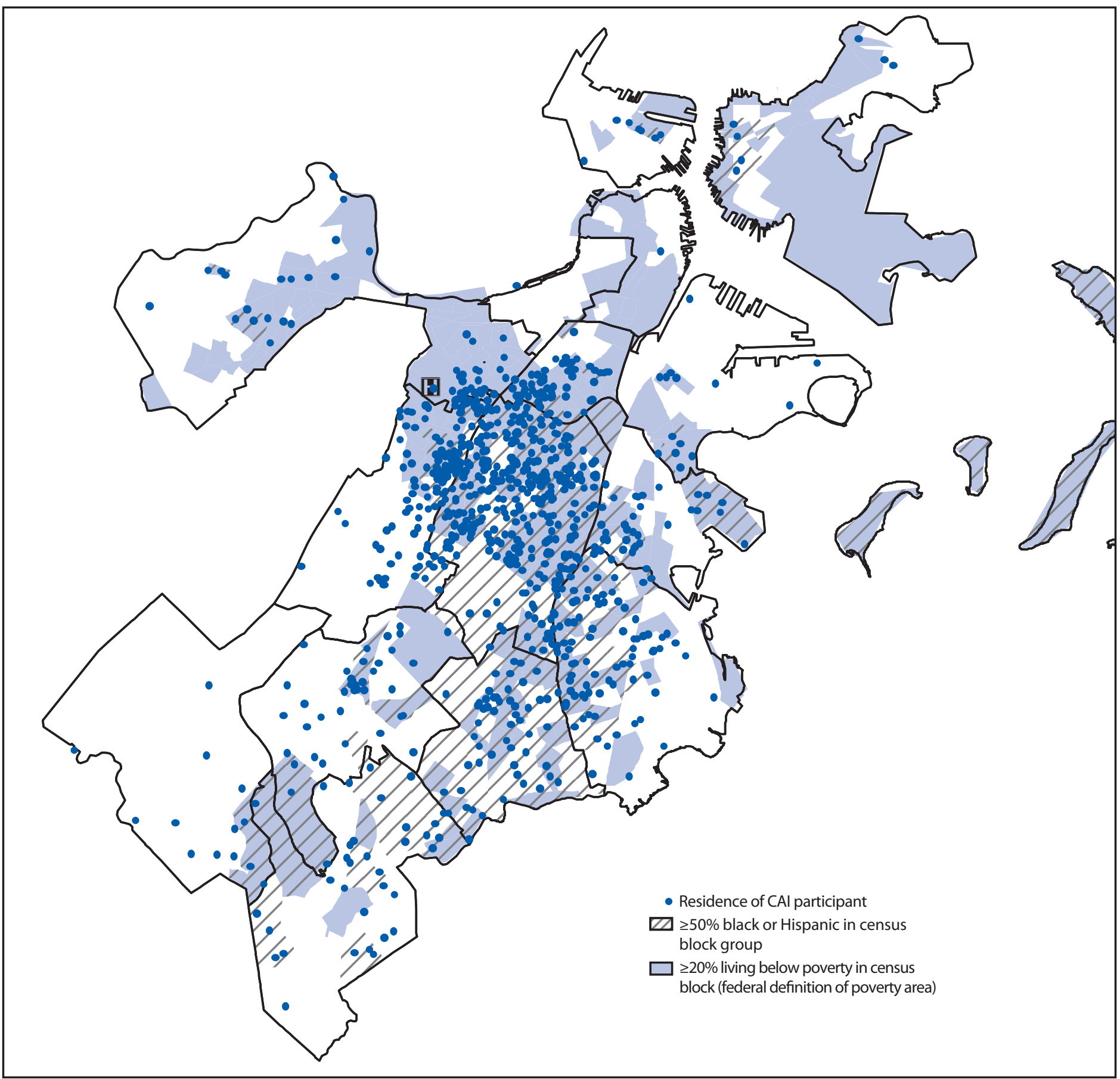

Abbreviation: $\mathrm{CAl}=$ Community Asthma Initiative.

${ }^{*} \mathrm{~N}=908$ participants served during the pilot and expanded program. A total of $66 \%$ of the CAI participants lived in a poverty area ( $\geq 20 \%$ of the population lives below the federal poverty level), and $74 \%$ lived in areas that are predominantly black or Hispanic. 
TABLE 6. Demographic and insurance characteristics of children in the Boston Children's Hospital Community Asthma Initiative (intervention group)* and children in similar neighborhoods (comparison group) during the pilot period - Boston, Massachusetts, October 1, 2005-June 30, 2008

\begin{tabular}{|c|c|c|c|}
\hline Characteristic & $\begin{array}{c}\text { Intervention } \\
\text { group } \\
(\mathrm{N}=268)\end{array}$ & $\begin{array}{c}\text { Comparison } \\
\text { group } \\
(\mathrm{N}=818)\end{array}$ & $p$ value \\
\hline Mean age, yrs & 6.9 & 6.1 & $0.34^{\S}$ \\
\hline $\begin{array}{l}\text { Sex, no. }(\%)^{\dagger} \\
\text { Male } \\
\text { Female }\end{array}$ & $\begin{array}{l}150(56) \\
118(44)\end{array}$ & $\begin{array}{l}468(57) \\
350(43)\end{array}$ & $0.72^{q}$ \\
\hline $\begin{array}{l}\text { Insurance, no. (\%) }{ }^{\dagger} \\
\text { Medicaid/MassHealth } \\
\text { Private }\end{array}$ & $\begin{array}{r}195(73) \\
73(27)\end{array}$ & $\begin{array}{l}556(68) \\
262(32)\end{array}$ & $0.14^{q}$ \\
\hline $\begin{array}{l}\text { Race/Ethnicity, no. (\%) }{ }^{\dagger} \\
\text { Hispanic } \\
\text { Black, non-Hispanic } \\
\text { Other }\end{array}$ & $\begin{array}{r}122(46) \\
110(42) \\
31(12)\end{array}$ & $\begin{array}{r}326(41) \\
382(48) \\
91(11)\end{array}$ & $0.22^{q}$ \\
\hline
\end{tabular}

* Boston Children's Hospital administrative data.

† Percentages do not include missing data and might not add to $100 \%$ because of rounding.

$\S$ Based on t-test.

I Based on chi-square test.

reports indicate a decrease in number of children with any (one or more) asthma-related hospitalizations and emergency department visits, and hospital administrative data indicate a decrease in mean number of asthma-related hospitalizations. The CAI model has been replicated in other cities and states, with adaptations to local cultural and system variations. Ongoing efforts for CAI and partners have included greater use of CHWs for home visits to decrease program costs and provide additional cultural and linguistic competency. Strong partnerships with public health, community, and housing agencies have allowed CAI to incorporate health outcomes and cost analyses into the business case to promote systemic changes locally and statewide to reduce asthma morbidity.

\section{References}

1. Akinbami L. National Center for Health Statistics health E-stat. Atlanta, GA: US Department of Health and Human Services, CDC; 2010. http:// www.cdc.gov/nchs/data/hestat/asthma03-05/asthma03-05.htm.

2. Akinbami LJ, Moorman JE, Bailey C, et al. Trends in asthma prevalence, health care use, and mortality in the United States, 2001-2010. National Center for Health Statistics Data Brief 2012; 94:1-7. http://www.cdc. gov/nchs/data/databriefs/db94.htm.

3. Evans R 3rd, Gergen PJ, Mitchell H, et al. A randomized clinical trial to reduce asthma morbidity among inner-city children: results of the National Cooperative Inner-City Asthma Study. J Pediatr 1999;135:332-8. http://dx.doi.org/10.1016/S0022-3476(99)70130-7.

4. Krieger JW, Takaro TK, Song L, Weaver M. The Seattle-King County Healthy Homes Project: a randomized, controlled trial of a community health worker intervention to decrease exposure to indoor asthma triggers. Am J Public Health 2005;95:652-9. http://dx.doi.org/10.2105/ AJPH.2004.042994.
FIGURE 3. Comparison of number of asthma-related hospitalizations and emergency department visits per child among children in the Boston Children's Hospital Community Asthma Initiative 1 year before and 1 year after the index visit* - Boston, Massachusetts

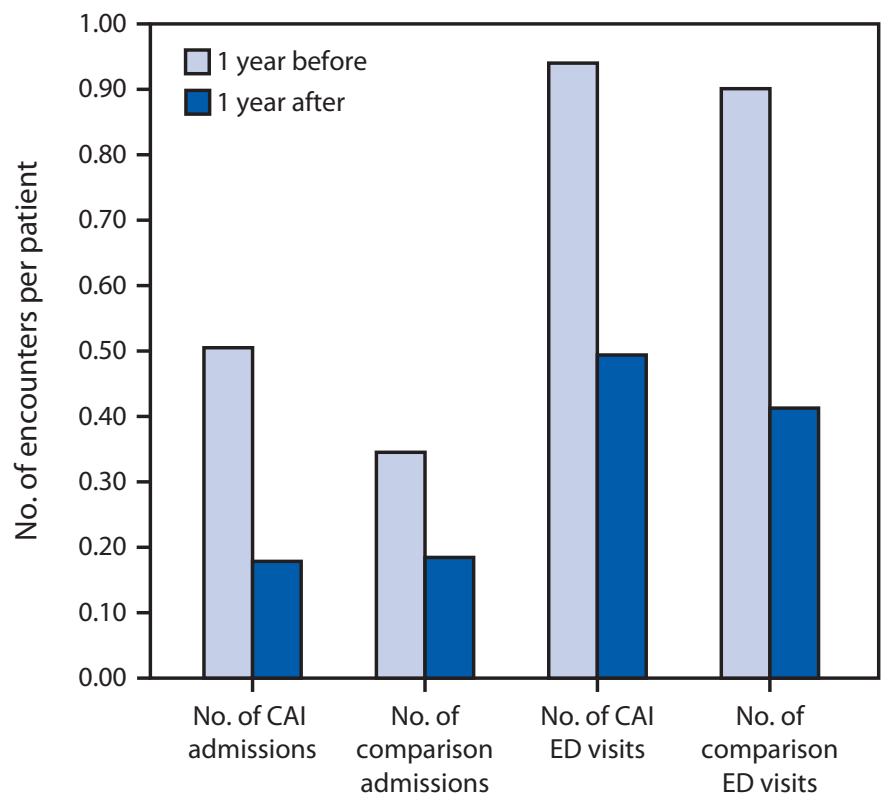

Abbreviations: $\mathrm{CAI}=$ Community Asthma Initiative; $\mathrm{ED}=$ emergency department * Obtained from CAl hospital administrative data $(\mathrm{N}=268)$ and children in similar neighborhoods (comparison group) $(\mathrm{N}=818)$ who had an asthma-related $E D$ visit or hospitalization 1 year before and 1 year after the index visit during the pilot period (index visits October 1, 2005-June 30, 2008). A significantly greater decrease occurred in mean number of hospitalizations per child for the intervention group compared with the comparison group from 1 year before to 1 year of follow-up $(p<0.001)$. No significant difference was found in the decrease in mean number of asthma-related ED visits per child between CAI participants and the comparison group $(p=0.49)$.

5. Morgan WJ, Crain EF, Gruchalla RS, et al. Inner-City Asthma Study Group. Results of a home-based environmental intervention among urban children with asthma. N Engl J Med 2004;351:1068-80. http:// dx.doi.org/10.1056/NEJMoa032097.

6. Krieger J, Jacobs DE, Ashley PJ, et al. Housing interventions and control of asthma-related indoor biologic agents: a review of the evidence. J Public Health Manag Pract 2010;16(Suppl):S11-20. http://dx.doi. org/10.1097/PHH.0b013e3181ddcbd9.

7. Nicholas SW, Jean-Louis B, Ortiz B, et al. Addressing the childhood asthma crisis in Harlem: the Harlem Children's Zone Asthma Initiative. Am J Public Health 2005;95:245-9. http://dx.doi.org/10.2105/ AJPH.2004.042705.

8. CDC. Reducing childhood asthma through community-based service delivery-New York City, 2001-2004. MMWR Morb Mortal Wkly Rep 2005;54:11-4.

9. Bryant-Stephens T, Kurian C, Guo R, Zhao H. Impact of a household environmental intervention delivered by lay health workers on asthma symptom control in urban, disadvantaged children with asthma. Am J Public Health 2009;99(Suppl 3):S657-65. http://dx.doi.org/10.2105/ AJPH.2009.165423.

10. National Heart, Lung, and Blood Institute, National Asthma Education and Prevention Program. Expert Panel Report 3: Guidelines for the diagnosis and management of asthma. Bethesda, MD: National Institutes of Health, National Heart, Lung, and Blood Institute; 2007. http:// www.nhlbi.nih.gov/health-pro/guidelines/current/asthma-guidelines. 
11. Task Force on Community Preventive Services. Recommendations from the Task Force on Community Preventive Services to decrease asthma morbidity through home-based, multi-trigger, multicomponent interventions. Am J Prev Med 2011;41(Suppl 1):S1-4. http://dx.doi. org/10.1016/j.amepre.2011.04.011.

12. Crocker DD, Kinyota S, Dumitru GG, et al. Task Force on Community Preventive Services. Effectiveness of home-based, multi-trigger, multicomponent interventions with an environmental focus for reducing asthma morbidity: a community guide systematic review. Am J Prev Med 2011;41(Suppl 1):S5-32. http://dx.doi.org/10.1016/j. amepre.2011.05.012.

13. Lieu TA, Quesenberry CP Jr, Capra AM, Sorel ME, Martin KE, Mendoza GR. Outpatient management practices associated with reduced risk of pediatric asthma hospitalization and emergency department visits. Pediatrics 1997;100:334-41. http://dx.doi.org/10.1542/peds.100.3.334.

14. Institute of Medicine. The future of the public's health in the $21 \mathrm{st}$ century. Washington, DC: The National Academies Press; 2003.

15. US Department of Health and Human Services. Healthy people 2020: disparities. Washington, DC: US Department of Health and Human Services; 2011. http://www.healthypeople.gov/2020/about/foundationhealth-measures/Disparities.

16. Boston Public Health Commission. Health of Boston 2010. Boston, MA; 2010. http://www.bphc.org/healthdata/health-of-boston-report/ Documents/HOB-2010/Health\%20of\%20Boston\%202010\%20 Full\%20Report_Rev16Nov10.pdf.

17. CDC. Learn how to control asthma. Atlanta, GA: US Department of Health and Human Services, CDC; 2014. http://www.cdc.gov/asthma/faqs.htm.

18. Lamb AK, Ervice J, Lorenzen K, Prentice B, White S. Reducing asthma disparities by addressing environmental inequities: a case study of regional asthma management and prevention's advocacy efforts. Fam Community Health 2011;34(Suppl 1):S54-62. http://dx.doi. org/10.1097/FCH.0b013e318202a81d.

19. Williams DR, Sternthal M, Wright RJ. Social determinants: taking the social context of asthma seriously. Pediatrics 2009;123(Suppl 3):S17484. http://dx.doi.org/10.1542/peds.2008-2233H.

20. Wright RJ, Mitchell H, Visness CM, et al. Community violence and asthma morbidity: the Inner-City Asthma Study. Am J Public Health 2004;94:625-32. http://dx.doi.org/10.2105/AJPH.94.4.625.

21. Curtis LM, Wolf MS, Weiss KB, Grammer LC. The impact of health literacy and socioeconomic status on asthma disparities. J Asthma 2012;49:178-83. http://dx.doi.org/10.3109/02770903.2011.648297.

22. Williams MV, Baker DW, Honig EG, Lee TM, Nowlan A. Inadequate literacy is a barrier to asthma knowledge and self-care. Chest 1998;114:1008-15. http://dx.doi.org/10.1378/chest.114.4.1008.

23. Koh HK, Berwick DM, Clancy CM, et al. New federal policy initiatives to boost health literacy can help the nation move beyond the cycle of costly 'crisis care.' Health Aff (Millwood) 2012;31:434-43. http://dx.doi. org/10.1377/hlthaff.2011.1169.

24. Smith LA, Bokhour B, Hohman KH, et al. Modifiable risk factors for suboptimal control and controller medication underuse among children with asthma. Pediatrics 2008;122:760-9. http://dx.doi.org/10.1542/ peds.2007-2750.

25. Massachusetts Department of Public Health, Center for Environmental Health. Pediatric asthma in Massachusetts: 2003-2004. Boston, MA: Massachusetts Department of Public Health; 2005. http://www.mass.gov/ eohhs/docs/dph/environmental/tracking/asthma-summary-20032004.pdf.

26. Boston Public Health Commission. Health of Boston 2005. Boston, MA; Boston Public Health Commission; 2005. http://medlib.bu.edu/ ebooks/HealthofBoston2005.pdf.
27. Bhaumik U, Norris K, Charron G, et al. A cost analysis for a communitybased case management intervention program for pediatric asthma. J Asthma 2013;50:310-7. http://dx.doi.org/10.3109/02770903.2013.765447.

28. Woods ER, Bhaumik U, Sommer SJ, et al. Community asthma initiative: evaluation of a quality improvement program for comprehensive asthma care. Pediatrics 2012;129:465-72. http://dx.doi.org/10.1542/ peds.2010-3472.

29. Penman-Aguilar A, Bouye K, Liburd L. Background and rationale. In: Strategies to reduce health disparities: selected CDC-sponsored interventions_-United States, 2016. MMWR Suppl 2016;65(No. Suppl 1).

30. City of Boston Inspectional Services Department. Breathe easy at home. Boston, MA: City of Boston Inspectional Services Department; 2015. http://www.cityofboston.gov/isd/housing/bmc.

31. Sommer SJ, Queenin LM, Nethersole S, et al. Children's Hospital Boston Community Asthma Initiative: partnerships and outcomes advance policy change. Prog Community Health Partnersh 2011;5:327-35. http://dx.doi.org/10.1353/cpr.2011.0044.

32. Bernstein R. Poverty areas. Washington, DC: US Census Bureau, Economics and Statistics Administration, US Department of Commerce; 1995. http:// www.census.gov/population/socdemo/statbriefs/povarea.html.

33. Bishaw A. Areas with concentrated poverty: 1999. Census 2000 special reports. Washington, DC: US Census Bureau; Economics and Statistics Administration; US Department of Commerce; 2005. http://www. census.gov/prod/2005 pubs/censr-16.pdf.

34. National Center for Healthy Housing. Pediatric environmental home assessment scenario. Columbia, MD: National Center for Healthy Housing; 2006. http://www.nchh.org/Portals/0/Contents/CHW_ PEHA_Materials_11.24.08.pdf.

35. Hoppin P, Jacobs M, Stillman L. Investing in best practices for asthma: a business case. August 2010 update. Boston, MA: Asthma Regional Council of New England; 2010. http://www.nchh.org/Portals/0/ Contents/Coalition_ARC_Best_Practices_\%20Asthma.pdf.

36. UMass Medical School Commonwealth Medicine. Massachusetts Medicaid pediatric high-risk asthma bundled payment pilot. Worcester, MA: UMass Medical School Commonwealth Medicine; 2011. http:// commed.umassmed.edu/sites/default/files/7128_Massachusetts $\% 20$ Medicaid\%20Pediatric\%20HighRisk\%20Asthma\%20Bundled\%20 Payment\%20Pilot\%20\%20September\%202011.pdf.

37. Institute of Medicine. Crossing the quality chasm: a new health care system for the 21 st century. Washington, DC: The National Academy Press; 2001.

38. Wessel L, Spain J. The chronic care model: a collaborative approach to preventing and treating asthma in infants and young children. Washington, DC: Zero to Three-National Center for Infants, Toddlers, and Families; 2005. http://www.clinicians.org/images/upload/Asthma.pdf.

39. Barnett AG, van der Pols JC, Dobson AJ. Regression to the mean: what it is and how to deal with it. Int J Epidemiol 2005;34:215-20. http:// dx.doi.org/10.1093/ije/dyh299.

40. Sommer SJ, Bhaumik U, Tsopelas L, et al. Boston Children's Hospital Community Asthma Initiative replication manual: needs assessment, implementation and evaluation. Boston, MA: Boston Children's Hospital; 2013. http://www.childrenshospital.org/ /media/Centers\%20 and\%20Services/Programs/A_E/Community\%20Asthma\%20Initiative/ ReplicationManual2CFinal2C92413.ashx. 